\title{
Colaborar e Aprender com Suporte Digital: possibilidades para a escola contemporânea
}

\author{
Maria Auricélia da Silva ${ }^{1}$, José Aires de Castro Filho ${ }^{2}$ \\ ${ }^{1}$ Unidade Universitária Federal de Educação Infantil Núcleo de Desenvolvimento da \\ Criança - Universidade Federal do Ceará (UFC) - Campus do Pici - Bloco 859 - \\ Fortaleza-CE \\ ${ }^{2}$ Instituto UFC Virtual - Universidade Federal do Ceará (UFC) - Campus do Pici - \\ Bloco $9011^{\circ}$ andar, Fortaleza-CE \\ silvauricelia@gmail.com, aires@virtual.ufc.br
}

\begin{abstract}
This article describes the accomplishment of a collaborative project with students of the 8th year of elementary school in a school contemplated with the One Computer Per Student (UCA) Project. The objective of the research was to analyze the use of collaborative tools to support pedagogical activities. The methodology used was participant research. The results indicated that the use of the Socrates environment and of Google Drive tools favored collective and collaborative production and are good resources to support learning.
\end{abstract}

Resumo. Este artigo descreve a realização de um projeto colaborativo com alunos do $8^{\circ}$ ano do Ensino Fundamental em uma escola contemplada com o Projeto Um Computador por Aluno (UCA). O objetivo da pesquisa consistiu em analisar o uso de ferramentas colaborativas como suporte às atividades pedagógicas. A metodologia utilizada foi a pesquisa participante. Os resultados indicaram que a utilização do ambiente Sócrates e de ferramentas do Google Drive favoreceram a produção coletiva e colaborativa e constituem bons recursos como suporte à aprendizagem.

\section{Introdução}

Atualmente, atividades mediadas pelas Tecnologias Digitais de Informação e Comunicação (TDIC) constituem uma prática capaz de favorecer a criação de novas metodologias, oportunizar a realização de experiências que utilizam o suporte de recursos tecnológicos e ferramentas online, muitas das quais colaborativas, para promover ensino e aprendizagem de conteúdos escolares.

Para tanto, fazem-se necessárias estratégias pedagógicas capazes de mobilizar professores e alunos em diferentes tempos e espaços, na perspectiva colaborativa. Mas será que a escola consegue integrar ao seu fazer cotidiano essas ações que acontecem fora dela? Como mobilizar os recursos digitais para apoiar práticas colaborativas, interdisciplinares, presenciais ou virtuais com as condições reais e efetivas da escola?

A implantação do Projeto Um Computador por Aluno (UCA), no período de 2010 a 2012, oportunizou o uso intensivo do computador e da Internet nas escolas 
VI Congresso Brasileiro de Informática na Educação (CBIE 2017)

Anais dos Workshops do VI Congresso Brasileiro de Informática na Educação (WCBIE 2017)

brasileiras contempladas. O referido Projeto teve como referência a proposta de distribuição de laptops para crianças pela Organização One Laptop per Children (OLPC), dirigida por Nicholas Negroponte.

A proposta brasileira, contudo, consistiu na inclusão digital dos professores, gestores e alunos de escolas públicas do País a partir da inserção de laptops educacionais em sala de aula. A partir desse Projeto, surgiram novos desafios e possibilidades para ensinar e aprender com o suporte da tecnologia.

Desse modo, o objetivo desta investigação consistiu em analisar o uso de ferramentas colaborativas como suporte às atividades pedagógicas, tendo como a metodologia utilizada a pesquisa participante.

Este artigo discute, portanto, a aprendizagem colaborativa com suporte computacional, apresenta a metodologia desenvolvida durante a realização da pesquisa e os resultados obtidos, os quais revelaram boas perspectivas para o trabalho colaborativo com suporte do laptop.

\section{Aprendizagem Colaborativa com Suporte Computacional}

A Aprendizagem Colaborativa com Suporte Computacional (CSCL) teve origem nas ciências que se ocupam da aprendizagem em grupo, especialmente quando o computador é utilizado como suporte. Como explicam Stahl, Koschman e Suthers (2006), o estudo da aprendizagem em grupos teve início antes dos anos 1960, mesmo quando ainda não existiam os computadores pessoais conectados em rede.

Sobre o surgimento da CSCL, é difícil assegurar quando ela despontou como um campo próprio de estudo ou como um paradigma emergente de ensino com tecnologia. A despeito de o primeiro workshop e a primeira conferência internacional sobre CSCL terem ocorrido em 1990 e em 1995, respectivamente, O'Malley e Scanlon já haviam usado o termo aprendizagem colaborativa apoiada por computador em 1989 [Liponnen, Hakkarainen e Paavola 2004].

Stahl, Koschman e Suthers (2006) afirmam que a ascensão da CSCL ocorreu nos anos 1990, em contraposição aos softwares que propunham a aprendizagem individual e isolada. Tal proposta, naturalmente, envolve uma mudança no conceito de aprendizagem, no fazer cotidiano da escola e nas formas de ensinar e aprender. Há que se considerar a aprendizagem do grupo e a de cada um de seus integrantes, pois ambas não se desvinculam, já que, como bem afirmam esses autores [2006, p. 4], "na CSCL, a aprendizagem é analisada como um processo do grupo, sem desconsiderar a análise da aprendizagem individual".

Desse modo, a CSCL tem como propósito a aprendizagem em grupo, em colaboração com outros estudantes, em lugar de aprender diretamente com o professor, numa relação que deixa de ser vertical e passa a ser horizontal, não-linear, heterárquica. Como propõe Lipponen (2002), a CSCL ocupa-se de compreender como a aprendizagem colaborativa apoiada pela tecnologia pode melhorar a interação e o trabalho e como a tecnologia pode favorecer o compartilhamento de conhecimentos e experiências entre os membros de um grupo.

Nesse processo, o docente desempenha um importante papel na oferta de suporte e orientação durante a realização das atividades, na mediação entre o conhecimento e os alunos, no acompanhamento dos caminhos que os estudantes percorrem para a busca de 
soluções, a construção coletiva do conhecimento e a produção dos resultados. Além disso, existem aspectos como distribuição do tempo, negociação das ideias, tomada de decisões, relações que se estabelecem entre os membros do grupo, que também são mediadas pelo professor, ainda que o faça mediante colaboração com os alunos [Silva, Barbosa e Castro-Filho 2013].

Almeida e Prado [2003, p. 53] reconhecem o papel do professor nesse processo, visto que a mediação docente deve ser "uma ação incitadora do diálogo, da representação do pensamento e do trabalho compartilhado, comprometido e solidário sendo exercitada tanto por ele como pelos demais participantes do ambiente por meio da proposição de estratégias adequadas”.

Abegg, Bastos e Müller (2010) defendem que o trabalho colaborativo em rede mediado pela tecnologia potencializa a formação social, favorece o crescimento do grupo, estimula o trabalho em conjunto e concorre para que os colaboradores desenvolvam uma compreensão mais profunda do conhecimento produzido coletivamente. As plataformas colaborativas, a partir da mediação docente, oportunizam a formação de coautores do conhecimento em lugar de formar, apenas, consumidores de informações produzidas por outrem.

Na concepção de Aparici e Acedo (2010), as tecnologias digitais favorecem a formação de redes de aprendizagem, nas quais se pode realizar um trabalho de colaboração. Contudo, para que o trabalho colaborativo se desenvolva, os autores ressaltam dois pontos imprescindíveis: coautoria coletiva e comunicação horizontal. Nesse sentido, Aparici e Acedo (2010) corroboram o pensamento de Lima (2008) e Abegg, Bastos e Müller (2010) ao enfatizar que a colaboração dos diferentes atores do processo colaborativo caracteriza-se pela coautoria, uma vez que a participação dos integrantes do grupo agrega valor à produção coletiva sem a preponderância de um autor sobre o outro. Todas as produções são discutidas e valorizadas, sem prioridade de autor, tempo ou espaço. A mudança nos papeis do professor e dos alunos constitui o eixo central e o suporte para a coautoria e a produção colaborativa [Castro-Filho, Silva e Maia 2015].

Percebe-se, portanto, a importância da ação docente, da concepção didática e da prática pedagógica desenvolvida para que a colaboração seja vivenciada. Assim, tornase imperioso aliar uma boa estrutura tecnológica a uma postura pedagógica consistente quanto ao trabalho colaborativo para que se obtenha êxito na CSCL.

\section{Percurso metodológico}

A pesquisa participante propõe alternativas de trabalho e elaboração de estratégias com os diversos segmentos populares, a fim de promover processos de produção e divulgação de conhecimentos construídos coletivamente. Le Boterf [1984, p. 52] esclarece que "a pesquisa participante vai [...] procurar auxiliar a população envolvida a identificar por si mesma os seus problemas, a realizar a análise crítica destes e a buscar as soluções adequadas".

Assim, a pesquisa participante foi eleita a metodologia desta investigação em razão dos seguintes pontos: a escola esteve comprometida com a pesquisa desde o lançamento da ideia pela pesquisadora, sentiu-se valorizada pela escolha do locus e desejava estudar e implementar novas estratégias de ensino e aprendizagem com suporte computacional; todos os passos da pesquisa foram negociados com os gestores e os 
VI Congresso Brasileiro de Informática na Educação (CBIE 2017)

Anais dos Workshops do VI Congresso Brasileiro de Informática na Educação (WCBIE 2017)

professores; a pesquisadora assumiu o compromisso de integrar-se à escola sem negar o fazer pedagógico já praticado cotidianamente; foram adotados o diálogo, a reflexão, a ação e o suporte computacional como elos mediadores em todo o processo de pesquisa.

\subsection{Locus, sujeitos da investigação e coleta de dados}

Esta pesquisa foi desenvolvida em uma escola do interior cearense participante do Projeto UCA, neste trabalho denominada Escola PAS, no ano de 2012. A opção por uma instituição contemplada com o Projeto UCA ocorreu em razão dos seguintes aspectos: utilização intensiva do laptop educacional nas atividades pedagógicas; acesso à Internet, fundamental para o trabalho em rede; crença nos aspectos relativos à conectividade, à mobilidade e ao modelo 1:1 como elementos que favorecem as práticas de aprendizagem colaborativa em rede; aquiescência da Escola e disponibilidade dos professores em colaborar com a pesquisa.

A execução do projeto colaborativo com as duas turmas de $8^{\circ}$ ano teve origem na sugestão de uma professora, que propôs o estudo do gênero textual ficção científica, conteúdo presente no plano de curso de Língua Portuguesa para a terceira etapa do ano letivo. A ideia foi acatada pelos outros dois professores que também lecionavam nessas turmas e, a partir de então, as demais atividades foram desenvolvidas a partir desse gênero textual e na obra Viagem ao Centro da Terra, do escritor francês Júlio Verne.

As duas turmas de $8^{\circ}$ ano funcionavam em turnos diferentes, uma pela manhã e outra à tarde, de modo que todas as atividades desenvolvidas entre os alunos foram virtuais, utilizando o ambiente virtual colaborativo Sócrates (Sistema Online para Criação de Projetos e Comunidades, algumas ferramentas do Google Drive e recursos do laptop educacional. A única atividade que as duas turmas realizaram presencialmente foi uma visita à X Bienal Internacional do Livro no dia 16/11/2012, no turno vespertino.

Como os professores e os horários de aula do $8^{\circ}$ ano eram os mesmos para os turnos manhã e tarde, os tempos destinados ao planejamento e à execução do projeto colaborativo repetiam-se nos turnos matutino e vespertino, o que facilitava $o$ acompanhamento da pesquisadora. Os professores foram nomeados P1 (Língua Portuguesa, História e Ensino Religioso), P2 (Matemática, Ciências e Arte) e P3 (Geografia e Inglês).

Foram realizados 17 (dezessete) encontros presenciais de duas horas-aula com cada turma (A e B), assim distribuídos: 10 (dez) encontros com o P1 (20 horas-aula) durante as aulas de Português; 04 (quatro) encontros com o P2 (08 horas-aula), sendo 02 para atividades de Matemática e 02 para Ciências; 03 (três) encontros com o P3 (06 horas-aula), para a realização das atividades de Língua Inglesa e participação dos alunos nas atividades propostas no ambiente colaborativo Sócrates.

No dia 12/12/2102, aconteceu a culminância do projeto, nos turnos manhã e tarde, para as respectivas turmas, com duração de 04 (quatro) horas-aula em cada turno. $\mathrm{Na}$ oportunidade, a comunidade escolar e os familiares acompanharam as apresentações feitas pelos alunos e o encerramento do Projeto, tendo como ponto principal o lançamento da coletânea de contos de ficção científica produzida pelos alunos, intitulada Ficção Científica: mito ou realidade? nas versões digital e impressa.

No tópico seguinte, será detalhado o desenvolvimento das ações realizadas durante o desenvolvimento do Projeto Ficção Científica: mito ou realidade? 
VI Congresso Brasileiro de Informática na Educação (CBIE 2017)

Anais dos Workshops do VI Congresso Brasileiro de Informática na Educação (WCBIE 2017)

\section{Resultados e discussão}

Neste tópico, é feita uma descrição geral de todas as ações realizadas para o planejamento e a execução do Projeto Ficção Científica: mito ou realidade?, a fim de que o leitor tenha uma visão mais ampla.

Para o desenvolvimento do projeto com os alunos, foi utilizado o ambiente colaborativo Sócrates (www.virtual.ufc.br/socrates), já conhecido dos professores e adequado ao trabalho com projetos. Para favorecer a produção coletiva, colaborativa e complementar as possibilidades da ferramenta Projetos, do ambiente Sócrates, foram utilizados recursos do Google Drive (formulário, texto e slides) e aplicativos do laptop, (editor de texto, Tux Paint) e outros que se fizessem necessários. Todas as ações planejadas entre os professores e a pesquisadora eram levadas aos alunos para diálogo e apreciação das ideias.

Criado o projeto e feito o planejamento inicial com os professores, tiveram início as atividades com os alunos no dia 16/10/2012. Como os discentes já haviam lido o livro e assistido ao filme Viagem ao Centro da Terra como atividades previstas pelo P1 na disciplina Língua Portuguesa, mas realizadas nas aulas dos três professores durante os momentos iniciais do planejamento do projeto, a ação seguinte foi a ambientação dos estudantes no Sócrates.

Para dar ciência aos pais dos alunos do $8^{\circ}$ ano sobre a realização desse projeto e contar com seu apoio, os professores e a pesquisadora enviaram aos pais dois formulários, mediante a anuência da gestão escolar: um para autorização de criação de emails e outro para uso da imagem, já que todas as atividades foram registradas em fotografia e em vídeo.

A partir da criação do projeto no Sócrates, foi necessário cadastrar todos os alunos das turmas A e B. Esse processo consumiu quatro aulas em cada turma, pois era necessário que os alunos tivessem email para fazer o cadastro no Sócrates. Mesmo para os alunos que já tinham email, foi necessário verificar se era ou não do Google. Como seriam utilizadas as ferramentas do Google Drive para compartilhamento das atividades, era imprescindível que todos tivessem Gmail. Foram duas aulas do P1 (16/10/2012) e duas aulas do P3 (18/10/2012) em cada turma para a consolidação desse processo. Ainda assim, foram necessários ajustes em aulas subsequentes, como: cadastro dos alunos faltosos e apoio aos que haviam esquecido a senha, aos que estavam com dificuldade de acessar o ambiente, além das dificuldades de acesso à Internet que, frequentemente, mantinha-se lenta.

O passo seguinte foi escolher um nome para o projeto. Para isso, os três professores e a pesquisadora solicitaram aos alunos que sugerissem nomes para votação. Os professores os incentivaram a criar os nomes e ficou combinado que a escolha do nome seria feito através da ferramenta formulário, do Google Drive. O P2, com a ajuda da pesquisadora, criou o formulário e o compartilhou com os alunos.

Na Figura 1, podem ser visualizados os nomes sugeridos pelos alunos e os títulos mais votados, do que resultou a escolha do nome Ficção Científica: mito ou realidade? 
VI Congresso Brasileiro de Informática na Educação (CBIE 2017)

Anais dos Workshops do VI Congresso Brasileiro de Informática na Educação (WCBIE 2017)

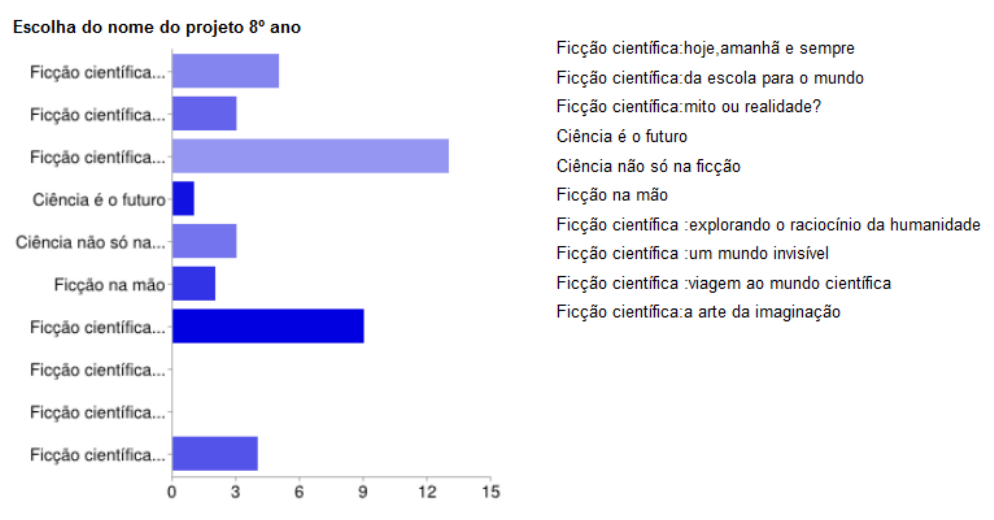

Figura 1 - Escolha do nome do projeto do 8 ano: formulário do Google Drive

A partir de então, o que se chamava provisoriamente Projeto do $8^{\circ}$ ano passou a ser denominado Projeto Ficção Científica: mito ou realidade? Este foi o título escolhido, com 33\% dos votos, dentre dez nomes criativos e interessantes. Dos 51 alunos das duas turmas, 40 estudantes votaram, o que foi considerado um número significativo de votos, isto é, $78 \%$ dos alunos.

O trabalho com os alunos foi realizado em grupos, nas duas turmas. A turma A tinha 25 alunos e a turma B, 26. Assim, cada uma foi dividida em cinco grupos de cinco alunos, sendo que um dos grupos da turma B ficou com seis alunos. Para evitar problemas com o deslocamento dos estudantes à escola no contraturno para a realização de atividades, os alunos do turno matutino não iriam à escola no turno vespertino, e vice-versa, mas trabalhariam com as mesmas atividades, usando os mesmos recursos, através da Internet.

Os grupos foram distribuídos por cores, sendo que os dois grupos de mesma cor, um da turma A e o outro da turma B, trabalhariam os mesmos temas e produziriam coletiva e colaborativamente. Para a distribuição dos grupos, as alunos escolheram um marcador de livro na cor de sua preferência (azul, amarelo, laranja, vermelho e verde) contendo uma imagem de Júlio Verne e a seguinte frase de sua autoria: "Não há nada impossível; há só vontades mais ou menos enérgicas".

As atividades planejadas pelos professores eram enriquecidas com as sugestões dos alunos. Assim, foram desenvolvidas as atividades pelos grupos das duas turmas, sob orientação dos professores.

O P1 orientou as seguintes atividades: produção de esquetes teatrais das partes principais do livro Viagem ao Centro da Terra; produção de contos de ficção científica; publicação impressa e digital de um livro de contos de ficção científica produzidos pelos alunos; visita à X Bienal Internacional do Livro, em Fortaleza.

O P2 acompanhou as seguintes ações: estudo de percentuais, gráficos e tabelas a partir da escolha do nome do projeto e de uma enquete sobre as preferências de leitura dos alunos do $8^{\circ}$ ano; estudo e produção de slides sobre os seguintes conteúdos presentes no livro Viagem ao Centro da Terra: regiões do oceano, minerais encontrados na Terra, vulcões, tipos de vegetação da Terra, camadas da crosta terrestre. 
VI Congresso Brasileiro de Informática na Educação (CBIE 2017)

Anais dos Workshops do VI Congresso Brasileiro de Informática na Educação (WCBIE 2017)

O P3 ficou responsável pelas seguintes atividades: estudo de autores de ficção científica, montagem de sua biografia, pesquisa sobre as principais obras e confecção de slides: J. K. Rowling, David Brin, Richard Matheson, Philip K. Dick, Isaac Asimov.

Ao longo do desenvolvimento do Projeto, os alunos participaram de fóruns no ambiente Sócrates, onde discutiam temas propostos pelos professores. Dentre eles, foi proposta uma sondagem de conhecimentos prévios sobre o gênero ficção científica, como pode ser visualizado na Figura 2:

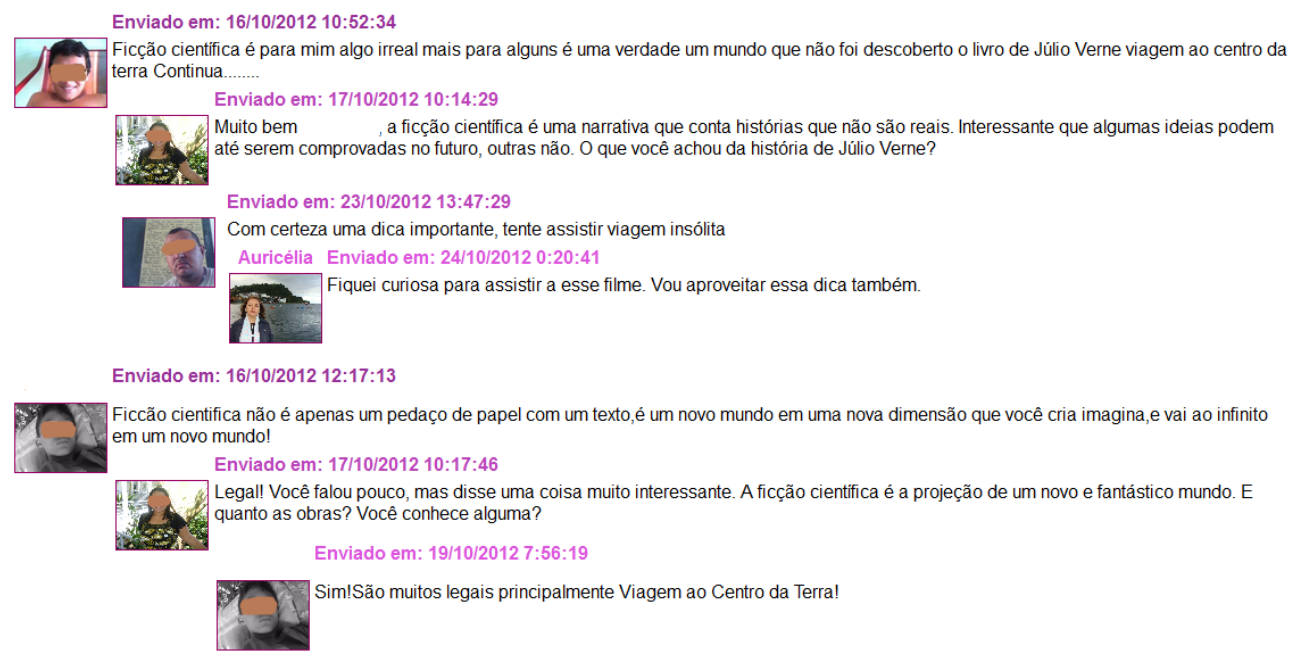

Figura 2 - Fórum 2: Conhecimentos prévios sobre o gênero ficção científica

Dentre as ferramentas do Google Drive, os alunos utilizaram as ferramentas de texto e slides para comporem e compartilharem suas pesquisas. Em alguns momentos, o acesso à Internet foi difícil, por isso os alunos utilizavam os recursos do laptop e, em seguida, postavam suas produções no Drive para que os colegas tivessem acesso e pudessem fazer alterações.

O produto final desse Projeto foi a publicação de uma coletânea de vinte e um contos produzidos pelos alunos, digitados por dois deles e corrigidos pelo P1 e pela pesquisadora. Os desenhos feitos pelos alunos, à mão ou usando aplicativos do laptop, foram inseridos no livro como ilustrações. Um deles foi escolhido pelos alunos para compor a capa do livrinho de contos.

Nem todos os alunos conseguiram produzir contos, mas colaboraram na produção de ilustrações para a coletânea e em outras ações importantes para a obtenção do objetivo comum, que era a publicação da coletânea pelas duas turmas. Os professores, por sua vez, compreenderam que os estudantes apresentam habilidades diferenciadas e estas concorrem para que o trabalho colaborativo se desenvolva mediante a colaboração em atividades diferenciadas.

A aprendizagem ocorreu a partir da ação dos estudantes em seu ambiente de convivência diária e de apropriação da cultura do seu grupo, mediados pelos professores, pelos colegas, pelos recursos tecnológicos, pelo entorno.

Uma limitação desse trabalho foi o fato de que nem todos os alunos produziram contos. Entretanto, participaram do processo criativo com desenhos, ilustrações, escolha das imagens para compor o livro, digitação dos textos, tudo isso de forma colaborativa. 
Como ressaltam Lave e Wenger (2002), o processo cognitivo e a comunicação situam-se num espaço pleno de significado, em um contexto histórico que representa o grupo, como no caso desses alunos. Os recursos tecnológicos, por sua vez, funcionaram como mediadores da aprendizagem [FREITAS, 2008], instrumentos que possibilitaram o acesso, a produção e a divulgação das produções dos alunos.

Como o acesso à Internet no distrito onde os alunos residem não era fácil, os professores sugeriram fazer uma versão impressa, além da digital. A versão digital foi publicada na Internet e a versão impressa, distribuída a todos os alunos durante a culminância do Projeto, em 12/12/2012.

Para o encerramento das atividades do Projeto, os professores P1 e P2 e os alunos prepararam as seguintes atividades: cordel elaborado pelo P1 e apresentado pelos alunos em forma de jogral; biografia de Júlio Verne e síntese das principais obras publicadas; exposição dos autores de ficção científica estudados pelos alunos; apresentação de slides com os conteúdos trabalhados em Ciências, inclusive a simulação de erupção vulcânica, técnica pesquisada e preparada pelo P2 e os grupos de cor laranja; paródia criada por um aluno. Os professores P1 e P2 apresentaram o evento, e os alunos apresentaram os trabalhos preparados.

Os alunos do $9^{\circ}$ ano e os pais dos alunos do $8^{\circ}$ ano foram convidados a assistir à culminância do Projeto, que aconteceu em cada turno para a respectiva turma, devido à dificuldade de locomoção dos alunos à escola no contraturno, pois a maioria usava o transporte escolar disponibilizado pelo município.

A presença dos pais na escola foi pensada para que eles conhecessem o trabalho que havia sido realizado com seus filhos, os resultados positivos alcançados com o trabalho pedagógico, estreitassem e relação família-escola e compreendessem como o Projeto UCA estava sendo desenvolvido na escola. Essa iniciativa já estava em andamento na Escola PAS e também foi relatada por Prado, Borges e França (2011) na escola UCA de Palmas, durante o pré-piloto, que convidava periodicamente os pais para conhecer o trabalho que estava sendo desenvolvido com seus filhos, a partir da inserção do laptop educacional.

\section{Conclusões}

Os resultados obtidos permitiram concluir que as ferramentas digitais utilizadas foram reconhecidas como recurso pedagógico, visto que houve aprendizagem de recursos tecnológicos online, ferramentas colaborativas que podem ser usadas em qualquer tempo e espaço, bem como alguns recursos do laptop.

O suporte virtual complementou a limitação da ausência dos alunos na Escola PAS e ofereceu as ferramentas necessárias ao trabalho colaborativo online. $\mathrm{O}$ ambiente Sócrates ofereceu o suporte para a discussão de ideias, a postagem de materiais, a organização e o registro das atividades com a segurança necessária ao trabalho escolar.

As ferramentas do Google Drive favoreceram a produção coletiva e colaborativa, posto que tais recursos têm essa função como foco. Ao lado dos aplicativos do laptop, foi possível vencer as dificuldades de acesso à Internet, ainda presentes e constantes na Escola PAS. De todo modo, houve trabalho colaborativo com uso de ferramentas propriamente colaborativas, como as do Google Drive, e ocasiões 
em que professores e alunos trabalharam colaborativamente, mesmo utilizando recursos que não tinham essa finalidade primordial.

O uso dos laptops na Escola PAS potencializou a realização do Projeto Ficção Científica: mito ou realidade? de uma forma que não seria tão favorável com o uso do Laboratório de Informática. O fato de todos os alunos e professores disporem de um laptop conectado à Internet favoreceu a produção colaborativa, o uso intensivo do suporte computacional e a própria realização das atividades em grupo, na sala de aula, pois o laboratório não suportaria a quantidade de alunos das duas turmas em termos de espaço físico nem a quantidade de acessos, pois os alunos utilizaram o laptop em, praticamente, todas as aulas destinadas ao Projeto nos meses de outubro a dezembro de 2012.

Como o trabalho colaborativo tem crescido nos últimos anos em todos os segmentos, convém ser ampliado na escola, sobretudo com a disseminação de dispositivos móveis que estão, cada vez mais, presentes no espaço escolar. Assim, esta temática deve ser aprofundada em investigações outras, que agreguem inovações e possam contribuir para o ensino e a aprendizagem, foco de tudo o que se pensa e faz em educação. Sobretudo, é importante pensar formas de aproveitar as experiências vivenciadas no Projeto UCA para desenvolver metodologias colaborativas, que favoreçam o ensino e a aprendizagem em um período bem mais favorável em termo de acesso a dispositivos móveis e à Internet.

\section{Referências}

Abegg, I., Bastos, F. P. e Müller, F. M. (2010) "Ensino-aprendizagem colaborativo mediado pelo wiki do Moodle", In: Educar em Revista, Curitiba, Brasil, n. 38, p. 205-218, set./dez. Disponível em: http://ojs.c3sl.ufpr.br/ojs2/index.php/educar/article/viewFile/13129/13530. Acesso em 10 jan. 2012.

Almeida, M. E. B.; Prado, M. E. B. B. (2003) "Criando situações de aprendizagem colaborativa". In: IX Workshop de Informática na Escola, pp. 53-60. Disponível em: http://br-ie.org/pub/index.php/wie/article/view/774/760. Acesso em 09 jan. 2012.

(2011) Indicadores para a formação de educadores para a integração do laptop na escola. In: Almeida, M. E. B.; Prado, M. E. B. B. (Org.) "O computador portátil na escola: mudanças e desafios nos processos de ensino e aprendizagem". São Paulo: Avercamp.

Aparici, R. e Acedo, S. O. (2010) "Aprendizagem colaborativa e ensino virtual: uma experiência no dia-a-dia de uma universidade a distância", In: Silva, Marco; Pesce, Lucila e Zuin, Antônio. Educação online: cenário, formação e questões didáticometodológicas. Rio de Janeiro: Wac Editora.

Damiani, Magda Floriana. (2008) "Entendendo o trabalho colaborativo em educação e revelando seus benefícios". Educar, Curitiba, Editora UFPR, n. 31, p. 213-230.

Fiorentini, Dario. (2006) Pesquisar práticas colaborativas ou pesquisar colaborativamente? In: Borba, Marcelo de Carvalho; Araújo, Jussara de Loiola (Orgs). "Pesquisa qualitativa em educação matemática". Belo Horizonte- MG: Autêntica, 2ed. 
VI Congresso Brasileiro de Informática na Educação (CBIE 2017)

Anais dos Workshops do VI Congresso Brasileiro de Informática na Educação (WCBIE 2017)

Freitas, Maria Teresa de Assunção. (2008) "Computador/internet como instrumentos de aprendizagem: uma reflexão a partir da abordagem Psicológica Histórico-Cultural". In: $2^{\circ}$ Simpósio Hipertexto e Tecnologias na Educação, Universidade Federal de Pernambuco.

Lave, Jean; WENGER, Etienne. (2002) "Prática, pessoa, mundo social". In: Daniels, Harry (Org.). Uma introdução a Vygotsky. São Paulo: Edições Loyola.

Le Boterf, G. (1984) "Pesquisa Participante: propostas e reflexões metodológicas”. In: Brandão, C. R. (Org.). Repensando a pesquisa participante. São Paulo: Ed. Brasiliense.

Lima, T. C. B. (2008) "Ação educativa e tecnologias digitais: análise sobre os saberes colaborativos". Tese de Doutorado. Fortaleza: Universidade Federal do Ceará.

Lipponen, L. (2002) "Exploring foundations for computer supported collaborative learning”. Department of Psychology, University of Helsinki, Finland. Proceedings of CSCL, page 72. Acesso em 18 nov. 2011.

Lipponen, L., Hakkarainen, K. e Paavola, S. (2004). "Practices and Orientations of Computer Supported Collaborative Learning". In: J. Strijbos, P. Kirschner \& R. Martens (eds.). What we know about CSCL, and implementing it in higher education (pp. 31-50). Boston, MA: Kluwer Academic Publishers. In: https://www.academia.edu/350359/Lipponen_L._Hakkarainen_K._and_Paavola_S._ 2004_Practices_and_orientations_of_CSCL Acesso em 28jul14.

Luckin, Rosemary et al. (2005) "Using mobile technology to create flexible learning contexts". Journal of Interactive Media in Education, (22). Disponível em http://jime.open.ac.uk/article/2005-22/299 Acesso em: 20 fev. 2012.

Roschelle, J.; Teasley, S. (1995). The construction of shared knowledge in collaborative problem solving. In: O’Malley, C. E., (ed.), "Computer supported collaborative learning". Pp. 69-97. Springer-Verlag, Heildelberg.

Silva, M. A., Barbosa, Jaiane Ramos e Castro-Filho, José Aires de. (2013) Aprendendo e ensinando colaborativamente com o suporte do laptop educacional. In: Anais do II Congresso Brasileiro de Informática na Educação 2013 - III Workshop sobre Formação e Experiências Educacionais no Programa Um Computador por Aluno. Campinas-SP, pp. 630-639.

Silva, M. A., Barbosa, Jaiane Ramos e Castro-Filho, José Aires de. (2015) Trabalho Colaborativo: aprendendo e ensinando com o laptop. In: CASTRO-FILHO, José Aires de; SILVA, Maria Auricélia da; MAIA, Dennys Leite (Orgs). Lições do Projeto Um Computador por Aluno: estudos e pesquisas no contexto da escola pública. Fortaleza: EdUECE.

Stahl, G., Koschmann, T. e Suthers, D. (2006). "Computer-supported collaborative learning: an historical perspective". In: R. K. Sawyer (Ed.), Cambridge handbook of the learning sciences (pp. 409-426). Cambridge, UK: Cambridge University Press. Disponível em: http://gerrystahl.net/cscl/CSCL_Portuguese.pdf in Portuguese. Acesso em 12 dez. 2011. 